\title{
Comparing the performance of models for wider economic benefits of transport infrastructure: results of a Dutch case study
}

\author{
Bert Hof • Arjan Heyma • Toon van der Hoorn
}

(C) The Author(s) 2011. This article is published with open access at Springerlink.com

\begin{abstract}
A case is set up concerning a fictitious Dutch high-speed railway project involving passenger transport. Direct welfare effects are calculated using a standard transport model. On the basis of the case description and the direct effects, five models calculate total welfare effects and wider (indirect) economic benefits. The results of these models are compared. In very broad terms, differences in results can be explained, but on a more detailed level, differences remain that are hard to explain. We also find that large differences in results are caused by differences in the way direct welfare effects are calculated, instead of by differences in wider economic benefits. This suggests that it pays a lot more to focus on understanding and improving direct effect calculations than to try and perfectly quantify wider economic benefits.
\end{abstract}

Keywords Cost benefit analysis - Wider economic benefits - Indirect economic effects . Model performance comparison

\section{Introduction}

Early 2009 a research project was completed that compared five models that are used for the evaluation of Dutch transport infrastructure investments (Hof and Heyma 2008). The aim was to compare outcomes of these models on the same case, specifically their

B. Hof · A. Heyma

SEO Economic Research, Amsterdam, The Netherlands e-mail: b.hof@seo.nl
A. Heyma
e-mail: a.heyma@seo.nl

T. van der Hoorn $(\bowtie)$

Section Policy Analysis and Forecasts (OVE), DVS Centre for Transport and Navigation, Rijkswaterstaat, Dutch Ministry of Infrastructure and Environment, PO Box 5044, 2600 GA Delft, The Netherlands

e-mail: toon.vander.hoorn@rws.nl 
calculations of indirect economic benefits [in the UK mostly denoted as wider economic benefits, see Eddington (2006)], and to assess whether differences in results could easily be explained. This paper summarizes the main findings of this project.

The case is a high speed passenger MAGLEV train connection from Schiphol Airport (Amsterdam; high population density) to Leeuwarden (capital of the province of Friesland in the north of the Netherlands; low population density). The case is fictitious, so that no model can have a comparative advantage from past studies or can calculate towards a result known before. Although fictitious, the case is based on existing proposed infrastructure projects so as to give reality to the exercise and to be able to make use of some existing information. Direct transport effects of the case are generated by the Dutch National Transport Model (LMS). These direct effects are inputs to the five models, on the basis of which they calculate additional wider economic benefits.

Our case study takes inspiration from the ISGLUTI study on urban land-use and transport interaction models (Webster et al. 1988). The studies differ, however, in two important ways. First, all our models concern a single country, the Netherlands. Second, our case is basically one instead of many 'simulations' and we are interested specifically in direct and indirect welfare effects.

The Dutch definition of indirect economic benefits was applied: costs and benefits that via market transactions are transferred to other markets than the transport market. Model owners were asked to explain the causes of the existence of additional wider economic benefits for the case and the main parameters in their model that influence the scale of these benefits.

The objective of this paper is threefold:

- To present the formal framework used for the definition and evaluation of wider (indirect) economic benefits by the central government in the Netherlands.

- To give an overview of the wide range of models claiming to deal with indirect effects.

- To report how the case study has tried to accomplish a common assessment methodology.

\section{Political context}

Although transportation modelling for policy analysis uses the rigorous methods of the exact sciences, it is not an exact science itself (see e.g. Talvitie 1997). There may be as many models and forecasts around as there are different opinions about the pros and cons of particular infrastructure policy measures. All too often forecasts are "massaged" to deliver the politically desired outcomes (Flyvbjerg et al. 2003). As an attempt to make an end to this Babylonic language confusion in the Netherlands, the OEI project was started. This resulted in mandatory guidelines for projects of the Dutch central government and for regional projects requesting central government subsidies.

The same should ideally be accomplished for models. The central government already uses a national transport model (LMS) and a series of transport models for regional applications (NRM). These are suitable for evaluating the direct economic effects of policy measures (changes in travel times and travel costs). Regional governments still use a wide variety of different models, for a large part due to preferences and historical reasons. For LUTI models (models for the interaction between land use and transportation) and models for the evaluation of wider (indirect) economic effects there is even less standardisation. 
The project presented in this paper was aimed at making further steps towards integration and maybe even to choose a preferred model.

It is clear that in such a political arena a rigorous academic exercise, with all the drivers of model differences under control of the researchers, is impossible. The conclusions from this study are, therefore, not universally valid, but they give guidelines on how to aim for consensus in an environment shaped by political realities.

\section{Market imperfections}

\section{The Dutch "OEI” guidelines}

This section summarizes Heyma and Oosterhaven (2005). Cost-benefit analysis (CBA) is obligatory in the decision-making process on all national transport investments in the Netherlands. Like the comparable UK report (SACTRA 1999), the Dutch "OEI guide" (Eijgenraam et al. 2000, later followed by various addenda) recommends to consider the question whether or not the "indirect economic effects" (in the UK mostly denoted as "wider economic benefits") of improving transport infrastructure represent additional welfare effects on top of the "direct transport effects" (time and cost savings) and the "direct external effects" (emissions, noise, etc.).

Infrastructure projects often have many effects outside the transport market. The transport costs of firms decrease, causing their profits to increase, and they might start to invest more. This may trigger cluster effects, agglomeration effects, and international competition effects. They may also, forced by competition, transfer their cost advantages partly or wholly to their customers, so that in the end also the prices for consumers will be reduced. Hence, the Dutch OEI guidelines recommend to carry out an integral CBA to investigate all indirect effects. However, one has to be very careful to prevent double counting and scrutinize in how far the indirect effects are truly additional.

In the Dutch OEI Guidelines the following definitions are given:

- Direct project effects Costs and benefits for owner, operator, and users of the project services. Welfare effect: integral. A correction is needed for users from/to abroad.

- Direct network effects Costs and benefits transferred via the transport market to other actors in the transport system. Most of these transfers will take place automatically via the markets. Additional welfare effect normally limited. A correction is needed for users from/to abroad.

- Direct external effects Costs and benefits of transport activities that-outside of any market - are transferred to others than the owner, operator, or users of the project services. Welfare effect: integral. A correction is needed for users from/to abroad.

- Indirect economic effects Costs and benefits transferred via market transactions to producers and consumers outside the transport market. Welfare effect only as far as additional. A correction is needed for users from/to abroad.

- Indirect network effects Costs and benefits transferred by indirect economic effects to actors within the transport system. Welfare effect only as far as additional. A correction is needed for users from/to abroad.

- Indirect external effects Costs and benefits transferred by indirect (economic and network) effects outside any market to others than the owner, operator, or users of the project services. Welfare effect: integral. A correction is needed for users from/to abroad. 
The OEI guidelines stipulate that the transferred indirect effects will be equal in size to the direct effects as long as market imperfections and border effects with countries abroad are nonexistent. In that case indirect effects do not cause additional welfare effects, as illustrated by the following analogy:

"A stone in a still pond does cause ever increasing rings, but the final water level increase is equal to the volume of the stone". Nevertheless, indirect effects often need to be evaluated to assess distributional effects on the welfare of various groups in society or to estimate external effects (e.g. changes in emissions outside the transport sector).

\section{Market imperfections in general}

Markets may be imperfect for various reasons. First, actors on markets usually take their own private costs and benefits into account but disregard the external costs and benefits caused by them to other actors. Second, the market price may be unequal to the private costs on the supply side, or unequal to the private benefits on the demand side. Such a difference may be caused by subsidies and taxes or by market power caused by economies of scale.

For example, when a new river crossing is built, car ferries may no longer be needed. If the car ferries were subsidized, the new bridge will lead to a reduction of the subsidies needed to fill the gap between price and average cost for the ferries. This represents an indirect additional benefit of the new bridge.

\section{Monopolies or oligopolies}

In unregulated monopolies or oligopolies, changes in monopoly profits represent additional welfare effects (see Rouwendal 2002). These profits result from economies of scale that are not passed on to consumers. An example is the improvement of a road to an airport holding a monopoly in a particular geographical area.

\section{Agglomeration economies}

Another category of welfare effects is economies of spatial agglomeration. If these (dis)economies are passed on through changes in prices, they will only produce additional welfare if the markets at hand work imperfectly, as indicated above. If they work perfectly, there is the risk of double-counting with the internal economies of scale at the firm level. An example is economies of scale for transport infrastructure in a newly developed large port area like the Tweede Maasvlakte in Rotterdam.

\section{Knowledge spillovers}

Most knowledge spillovers are either passed on as part of regular customer/supplier relations or by people moving from one firm to another. In such cases, the market price or the wage paid accounts for the knowledge passed on. Only when additional knowledge is passed on outside market transactions for free, for example during informal meetings, a truly external effect occurs that has to be added in full to the direct effect. An example is Silicon Valley. 
Product variety

Monopolistic competition potentially induces yet another kind of additional welfare effect. The standard Dixit-Stiglitz (1977) model of monopolistic competition provides the theoretical core of the so-called 'new economic geography' (NEG) models. Competition drives down the price to the average cost and monopoly profits to zero, but product variety through differentiation (e.g. different brands) still allows producers the market power needed to set their prices above marginal cost. New infrastructure and shorter travel times may lead to a larger variety of supply that represents an additional welfare effect (Rouwendal 2002). An example of product variety is a rail system with first and second class.

Labour market imperfections

Of all markets, the labour market is probably, and in the Netherlands definitely, the most imperfect one. At the national level there is a large gap between the gross wage cost for the employer and the net wage for the employee. The social security safety net reduces the willingness of people to take a job. The consequence is a considerable amount of inactivity. Finally, most wages are nationally set in bilateral negotiations between labour and employer unions and declared binding. In this situation, for example a new road to a remote area will have additional indirect effects over and above the direct effects.

\section{Land market imperfections}

The Netherlands has a tradition of heavily regulating the land market. Prices, especially in the owner-occupied housing market and in the real estate office market, are rather flexible. However, land prices are distorted by zoning regulations and all kind of subsidies. In this situation, for example a new road to a remote area will not lead to adjustment of real estate prices as in a free market, and there will be additional indirect effects over and above the direct effects.

\section{The models under consideration}

Five models for wider economic benefits participated in the research project: RAEM-2, REMI-NEI, CGEurope, MOBILEC and TIGRIS-XL. Since the last model does not calculate effects in monetary terms, the results were not comparable to the results of the other models. RAEM-2 and CGEurope are general equilibrium models, with CGEurope having a specifically European context. REMI-NEI in first instance calculates the transfer of direct welfare effects, while additional wider economic benefits are calculated in separate additional runs of the model. MOBILEC calculates total effects and does not distinguish between direct and indirect effects, at least not according to standard definitions.

Direct effects in the case, consisting of savings in travel times and costs, were generated by the Dutch National Transport Model (LMS) (Daly and Sillaparcharn 2008). Its development started in 1984. Recently, a major upgrade was completed (Willigers and de Bok 2009), but this new version of the model system was not available for our study. The model system consists of disaggregate discrete choice models and comprises some 1,500 zones. The basic unit is the "tour", i.e. a chain of trips starting and ending at home. The mobility choices that are simulated include: tour frequency, mode and destination choice, time of 
day choice, secondary and lower level destinations and the choice of a train route. These models are estimated on a large Dutch National Travel Survey.

The model includes three periods: morning peak, off-peak and evening peak. LMS distinguishes five home based travel purposes and two work-based purposes (business and other work-based travel). The demand model, covering mode-destination and time of day choice, iterates with the network assignment model (QBLOK), to determine the equilibrium travel times taking the influence of congestion on travel times and mode/destination choice into account.

The direct effects from LMS are input to the models for wider economic benefits. Some of these models, however, are capable of calculating direct effects themselves. In that case, the model owners can make a choice for (i) using the LMS results (RAEM-2 and REMINEI) or for (ii) recalculating the direct effects (CGEurope, MOBILEC). TIGRIS-XL uses the direct effects from LMS, because LMS is closely integrated within it.

Direct economic benefits consist of a reduction of travel costs and travel times multiplied by the value of time (VOT) for the users of transport services and the extra operational income for the owner/operator of the transport service. The VOT's come from a large dedicated Dutch Stated Preference study in 1997. The direct user benefits consist of those for the existing train users and those of the new train users (mostly coming from car). The latter have been calculated using the rule-of-half (see e.g. Jara-Díaz 2007). The operational incomes of all operators are assumed to be equal to the total fare proceeds. The extra operational income is, thus, calculated as the total travel costs in the project alternative minus the total travel costs in the reference alternative. On the level of total society the balance of extra travel costs paid by the travellers and extra income for the operators is zero, but it may be relevant to show the distributional effects of the project for different groups separately.

\section{The REMI-NEI model}

REMI-NEI (Fan et al. 2000; Bork and Van Treyz 2005) is an interregional input-output model comprising elements from NEG and general equilibrium. The core of the model consists of regional production functions that depend on product prices, wages and generalized transport costs.

Spatial detail Seven regions within the Netherlands, one foreign region.

Transport details No transport model, but the economic model depends on generalized transport costs for freight, commuting, business trips, and other transport purposes. Wider economic effects are computed through commuting and business trips only.

Direct effects applied From LMS.

Wider economic effects

Economies of scale/agglomeration economies Product markets operate in monopolistic competition, with economies of scale and agglomeration economies (production depends on the nearness of suppliers and employees). These economies increase when the generalized transport costs of business trips are reduced.

Knowledge spillovers Not modelled.

Product variety Product variety increases with an increase in labour supply, for instance as a result of reduced commuting costs.

Labour market imperfections Wages adjust slowly to changes in the supply and demand of labour, which has consequences for the unemployment level. Reduced commuting 
costs lead to higher labour supply and higher labour demand. Changes in the unemployment level may lead to additional costs or benefits.

Land market imperfections Not modelled.

Macro-economic feedback Commuting costs affect labour supply, which is a factor in the regional production functions.

Cross-border effects Foreign business passengers benefit from lower transport costs.

Taxation The sum of benefits minus investments per annum are added to the yearly income of households, leading to adjustments in expenditures and labour supply.

Calculation of wider economic effects All welfare gains from wider economic effects are calculated in separate runs outside the model.

\section{The RAEM-2 model}

The RAEM-2 model (Oosterhaven et al. 2001; Thissen 2005) belongs to the class of general equilibrium models and fits in the NEG theory. An important remark for this case study is that the version of RAEM used is a static equilibrium model. After completion of our study an experimental dynamic version of RAEM has been developed, which calculates changes on a period-by-period basis.

Spatial detail 40 "COROP" areas in the Netherlands, no foreign area.

Transport details No transport model. The general equilibrium model depends on generalized transport costs for workers (commuting) and producers (business trips). Wider economic effects are computed through commuting only.

Direct effects applied From LMS, commuting only.

Wider economic effects

Economies of scale/agglomeration economies Product markets operate in monopolistic competition, with perfect competition as a special case. Economies of scale result from increased production levels. Reduced commuting costs increase labour supply and enable these higher production levels. Agglomeration economies depend on the estimated degree of competition on the different product markets, and increase when sectors benefit from having more firms in their neighbourhood.

Knowledge spillovers Not modelled.

Product variety Reduced commuting costs lead to higher production via increased labour supply, which translates into a larger product variety as a result of monopolistic competition.

Labour market imperfections The labour matching approach allows for incomplete matches, which results in unemployment and vacancies. Reduced commuting costs lead to higher commuting and lower migration, which determine the regional supply of labour. Additional costs and benefits of changes in unemployment and vacancies (tax receipts and unemployment benefits) are explicitly modelled.

Land market imperfections Not modelled.

Macro-economic feedback Commuting costs affect the regional labour supply, which determine the regional production possibilities.

Cross-border effects Not modelled.

Taxation Not modelled.

Calculation of wider economic effects All welfare gains from wider economic effects are calculated within the model. Ratio between calculated direct and indirect effects is used to calculate total indirect effects from commuting based on total direct effects of 
commuting from LMS. Direct effects calculated by the model may differ from those by LMS as a result of endogenous commuting.

\section{The CGEurope model}

The CGEurope Model (Bröcker 2002) is a comparative static spatial computable general equilibrium model for Europe. The European context distinguishes it from the other models, which are basically national models for the Netherlands.

Spatial detail 40 COROP areas in the Netherlands, 1,341 regions worldwide.

Transport details No transport model. The general equilibrium model depends on generalized transport costs for producers (business trips). Wider economic effects are computed through business trips only.

Direct effects applied Recalculation of travel time savings, applied to business trips only.

\section{Wider economic effects}

Economies of scale/agglomeration economies Product markets operate in monopolistic competition, with economies of scale and agglomeration economies. These economies increase when the generalized transport costs of business trips are reduced.

Knowledge spillovers Not modelled.

Product variety Reduced costs of business trips lead to higher production, which translates into a larger product variety as a result of monopolistic competition.

Labour market imperfections Not modelled. Regional labour markets clear by wage adjustments, allowing for commuting, but labour is immobile (no migration).

Land market imperfections Not modelled.

Macro-economic feedback Reduced costs of business trips increase production levels and thereby labour demand. As a result of fixed labour supply, wages increase, which reduces production.

Cross-border effects Foreign business passengers benefit from lower costs of business trips.

Taxation Not modelled.

Calculation of wider economic effects Welfare gains from wider economic effects are calculated as the difference between total effects generated by the model and direct effects of business trips generated by the model.

\section{The MOBILEC model}

MOBILEC (Van de Vooren 2004) is a neoclassical production growth model, enhanced by a two-way interaction between transport and the economy. Each region has a regionspecific production function, with a causal direction from mobility to the economy. Traffic infrastructure is viewed as another production factor, besides labour and capital. Although only the part of infrastructure that is used for production is included in the production function, the dependence of production on the amount of transport instead of transport prices results in strong multiplier effects of investments in infrastructure.

Compared to the Dutch CBA manual, MOBILEC uses a different definition for direct and indirect effects. Direct welfare effects are defined as "the changes in welfare due to the enlargement of the public capital stock". The (additional) indirect welfare effect is defined as "the consequence of this enlargement", especially the growth in domestic product. 
Spatial detail 40 COROP areas in the Netherlands, 3 cross-border areas (Germany, Belgium/Luxembourg and France).

Transport details No transport model, but the economic model depends on generalized transport costs for commuting, business trips, educational trips, shopping trips and other transport purposes.

Direct effects applied Recalculation of generalized travel costs by the adjustment of the intensity-capacity ratio. This ratio between transport demand and supply by infrastructure, expresses the amount of congestion.

Wider economic effects

Economies of scale/agglomeration economies None, product markets are assumed to operate in perfect competition.

Knowledge spillovers Not modelled.

Product variety Not modelled.

Labour market imperfections Not modelled.

Land market imperfections Not modelled.

Macro-economic feedback Investments in infrastructure increase production, which may increase transport demand and-with given levels of infrastructure-congestion (intensity-capacity ratio), and thereby transport costs, eventually reducing production levels.

Cross-border effects International relocation of production to and from Germany, Belgium/Luxembourg and France is accounted for.

Taxation Not modelled.

Calculation of wider economic effects The model makes no distinction between direct and wider economic effects. Total effects are calculated based on changes in travel flows and travel times through their effect on production.

\section{The TIGRIS-XL model}

TIGRIS-XL is a Land Use Transport Interaction Model (LUTI model) (Zondag 2007; Zondag et al. 2007). It is a system consisting of dynamic interactions between five submodels, addressing specific markets. It was developed after a preliminary study (van der Hoorn and Schoemaker 2002), where the feasibility of several LUTI models was assessed: MEPLAN, TRANUS, Oregon Statewide Integrated Land Use and Transport Model, IRPUD, URBANSIM, MUSSA, and the New York Metropolitan Transportation Council Land Use Model (NYMTC-LUM). Besides the international state-of-the-art LUTI models three Dutch models were included: RAEM, the Environment Explorer (LOV), and MOBILEC.

The five sub-models in TIGRIS are: (i) the demographic module, (ii) the land market module, (iii) the housing market module, (iv) the labour market module and (v) the transport module. TIGRIS-XL is essentially a spatial model that distributes given national totals over zones.

The land-use modules use time steps of 1 year. TIGRIS-XL is fully integrated with the National Transport Model (LMS), since the two models, land-use and transport, interact every 5 years. Many sub-models in TIGRIS-XL have been empirically estimated on actual data.

Since TIGRIS-XL (at this time) does not calculate effects in monetary terms (additional) welfare effects cannot be derived from the model. However, because of its foundation on the international state-of-the art in LUTI models and its seamless integration with 
LMS it is the preferred candidate for extension with such a module. A working plan has been defined based on the link between agglomeration and productivity, as proposed by Graham (2005).

Spatial detail 40 COROP areas in the Netherlands, no cross-border area.

Transport details Full integration with LMS

Direct effects applied From LMS.

Wider economic effects

Economies of scale/agglomeration economies Product markets are not modelled, but agglomeration economies are used to distribute labour demand across regions. Reduced transport costs thus lead to agglomeration economies.

Knowledge spillovers Not modelled.

Product variety Not modelled.

Labour market imperfections Not modelled.

Land market imperfections Not modelled. Several exogenous assumptions can be made about government zoning regulations and the location choices of firms affecting land use. However, land prices are not included in the model. The housing market is modelled in detail, where housing prices result from the match between demand and supply.

Macro-economic feedback Not modelled. The national level of activities is fixed, the allocation across regions is variable.

Cross-border effects: Not modelled.

Taxation Not modelled.

Calculation of wider economic effects The model expresses effects in relocation of the population (labour supply) and firms (labour demand) across regions, but does not determine (changes in) prices and therefore does not generate (monetary) welfare effects.

\section{Results}

In Fig. 1 and Table 1 we give a summary of the results. They concern the year 2020 and are in millions of euro's.

Fig. 1 Models and economic benefits, mln euro's, 2020, all scaled to 365 days per year

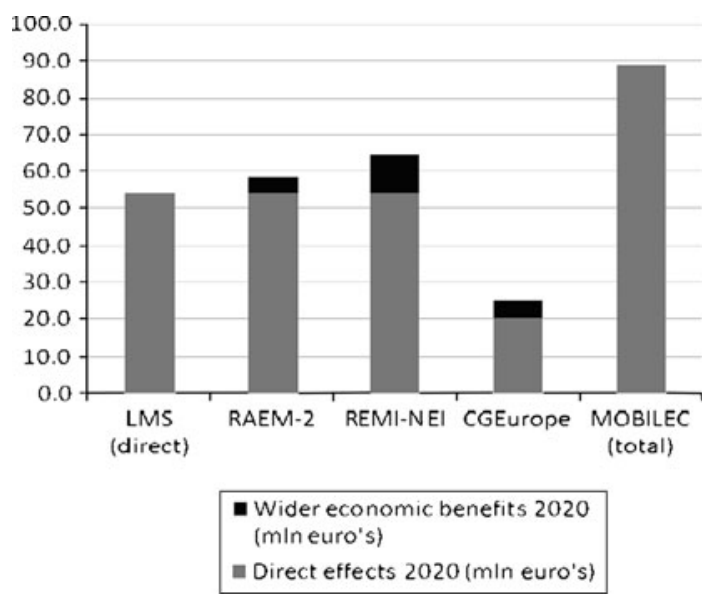


Table 1 Models and contributions to additional wider economic benefits, mln euro's, 2020, 365 days per year

\begin{tabular}{lcccc}
\hline & RAEM-2 & REMI-NEI & CG-Europe & MOBILEC \\
\hline Total effects & 58.3 & 61.9 & 25.2 & 88.8 \\
Direct & 54.3 & 54.3 & 20.4 & 88.8 \\
Wider & 4.0 & 6.7 & 4.8 & 0 \\
$\quad$ Taxation & 0.0 & -3.6 & 0.0 & \\
Foreign countries & 0.0 & 1.7 & 1.0 & \\
Production, consumption, labour market & 4.0 & 8.6 & 3.7 & \\
$\quad$ Production and consumption & & 0.0 & 3.7 & \\
$\quad$ Labour market & & 8.6 & 0.0 & \\
\hline
\end{tabular}

First take a look at Fig. 1. Total effects are in the same order of magnitude for LMS (direct effects of the transport model), RAEM-2 and REMI-NEI. CGEurope calculates smaller effects and MOBILEC calculates substantially larger effects. These differences are caused mainly by differences in direct welfare effects, and to a much lesser extent to differences in additional wider economic benefits. The additional indirect effects as a percentage of direct effects are in the range of $0-30 \%$, believed to be valid in the Netherlands on the basis of limited empirical results (Elhorst et al. 2004). Essentially, both CGEurope and MOBILEC recalculate direct welfare effects. In addition, CGEurope uses only the direct effects of business passengers from LMS, explaining the lower value of direct effects.

Now consider Table 1, which gives a summary of the contributions to additional wider economic benefits. We give some comments row by row.

Total effects The model MOBILEC does not calculate additional wider economic benefits, but total effects only, including recalculated direct effects.

Indirect effects of taxation REMI-NEI is the only model that calculates indirect effects of taxation, although we do not consider the results of that exercise plausible.

Foreign countries REMI-NEI and CGEurope calculate additional wider economic benefits generated through exchanges with foreign countries based on travel time reductions of business passengers. (Recalculated) travel time savings are applied to international trips. The international indirect effect in REMI-NEI goes through export/import and jobs, which leads to higher additional indirect effects than in CGEurope.

Additional indirect effects through production and consumption REMI-NEI calculates these as being close to zero. Since travel costs affect production possibilities, wider economic effects in principle are caused by scale effects and cluster effects (through product variety), which in REMI-NEI depend on changes in generalized travel costs of business passengers. These changes turn out to be relatively small. In CGEurope, changes in generalized travel costs of business passengers also cause indirect effects through changes in product variety, but here a recalculation of direct effects leads to bigger effects. In RAEM2 it is not possible to separate additional indirect effects via the labour market and additional indirect effects via production and consumption. Only the total is shown.

The effect on product variety in RAEM 2 runs through the regional supply of labour, which depends on commuting, which in turn depends on the direct effects of commuting from LMS.

Indirect labour market effects Both RAEM-2 and REMI-NEI calculate these on the basis of the direct effects of commuting. Commuting costs affect labour supply per region. 
Changes in labour supply have consequences for tax receipts and unemployment benefits, which lead to wider economic effects. In RAEM-2, these effects are calculated within the model, which gives a ratio of indirect to direct effects. This ratio is applied to the direct effects of commuting from LMS in order the calculate the ultimate additional indirect effects. REMI-NEI calculates labour market effects in a separate run of the model. Independently of the model, assumptions are made on crowding out of low skill workers by high skill workers and on unemployment, and the resulting effects are valued through their effects on taxes and (unemployment) benefits.

A final remark is that in all the models in this study both the land and housing market are missing as potential causes for wider economic benefits, although significant imperfections do exist in these markets.

\section{Explaining differences in results}

The results of these models can, in general, not be said to be 'right' or 'wrong', simply because we do not know the true value of the additional wider economic benefits. The high-speed rail line project is not a real one. More generally, in practice we do not observe both the effects of realization of the project and the effects of not realizing it at the same time. There is no absolute benchmark to which to compare the model results. A 'softer' criterion is the plausibility of model results and the extent to which differences in model results can be explained. The explanations given by the model owners play an important role here.

In general, differences in model results can potentially be attributed to:

- differences in data that are used as input to the models;

- the way the models use these inputs (and where these inputs are modified);

- the theoretical structure of the models;

- the value of specific parameters of the models;

- the way in which the output is expressed; and

- differences in the specification of what the world looks like without the project.

In this case study, all models were given the same inputs. Model owners were asked to present their output in a specified format which was held the same for all models. Model owners were also asked to use the same background scenario. Differences in results can therefore be attributed to differences in the way the inputs are used by the models, differences in theoretical model structure and differences in model parameters.

In this paper it is impossible to present all comparisons in detail, see for this Hof and Heyma (2008). The major part of the differences in model outcomes is caused by the following elements:

- Total effects in CGEurope are considerably lower, because direct effects only concern business passengers, whereas RAEM-2 and REMI-NEI set direct effects equal to the ones supplied from LMS.

- If the indirect effects of taxation are not taken into account, total effects in REMI-NEI are higher than in RAEM-2, because of higher indirect effects through exchange with foreign countries and through the labour market. In addition, double counting of indirect effects may play a role as well.

- Indirect effects in CGEurope are somewhat higher than in RAEM-2, especially because CGEurope takes account of indirect effects through exchange with foreign countries. 
- MOBILEC uses a different definition of direct and indirect economic effects than in the OEI guidelines. Moreover, the economic benefits from MOBILEC are substantially larger than those calculated by other models. The implied indirect effects are not in the plausible range of $0-30 \%$ as mentioned in the literature (Elhorst et al. 2004). There is no clear reason why.

\section{Summary table (with + and - ratings)}

See Table 2.

\section{Conclusions and discussion}

The main observations in this case study are that wider economic benefits in the models under consideration are relatively small compared to direct economic benefits and that differences in model outcomes are caused mainly by differences in direct welfare effects calculations. This leads us to conclude that. Given the real-life problems of calculating costs en benefits by models, it pays more concentrate on further improving the (model) calculation of direct effects than to focus too much on detailed calculations of wider economic benefits. A question for further research involves the extent to which these conclusions carry over to other models and/or other countries. Our conclusion does not mean that one should ignore wider economic benefits altogether. On the contrary, this distinction particularly serves to prevent double counting of benefits.

The comparison has shown that the reasons for the existence of additional effects in the models caused by market imperfections still remain partly unclear. Models are still a black box. This implies that cost-benefit analyses based on these models are partly a black box as well. This is not helpful for project evaluation. Although these observations are based on the models as used in this case study only, our fear is that they can be equally valid for other models used for cost-benefit analyses as well.

From our study, and especially from the summary table in the previous section, it is clear that for the Netherlands there is no dominant model yet that can be used as the standard for the future. Every model has its pros and cons. We believe that, in general, the following criteria are relevant and realistic for a preferred model for indirect economic benefits:

1. Preferably, it has an interface with national and/or regional transport models. Direct effects from these models can be used as input to the model for indirect economic benefits. This requires consistency in time horizon, socio-economic input, zoning systems, number of days, etc.

2. All passenger travel purposes must be included, as well as freight transport.

3. It must be dynamic, showing a time path between base and forecasting year.

4. It must be able to deal with border crossing effects.

5. It must be estimated on empirical transport behaviour.

6. It must be able to run in two modes: (i) a quick scan to see whether indirect effects are significant or not altogether (ii) a detailed mode to perform an accurate CBA of a specific project. This is because indirect effects are often small compared to direct effects. 


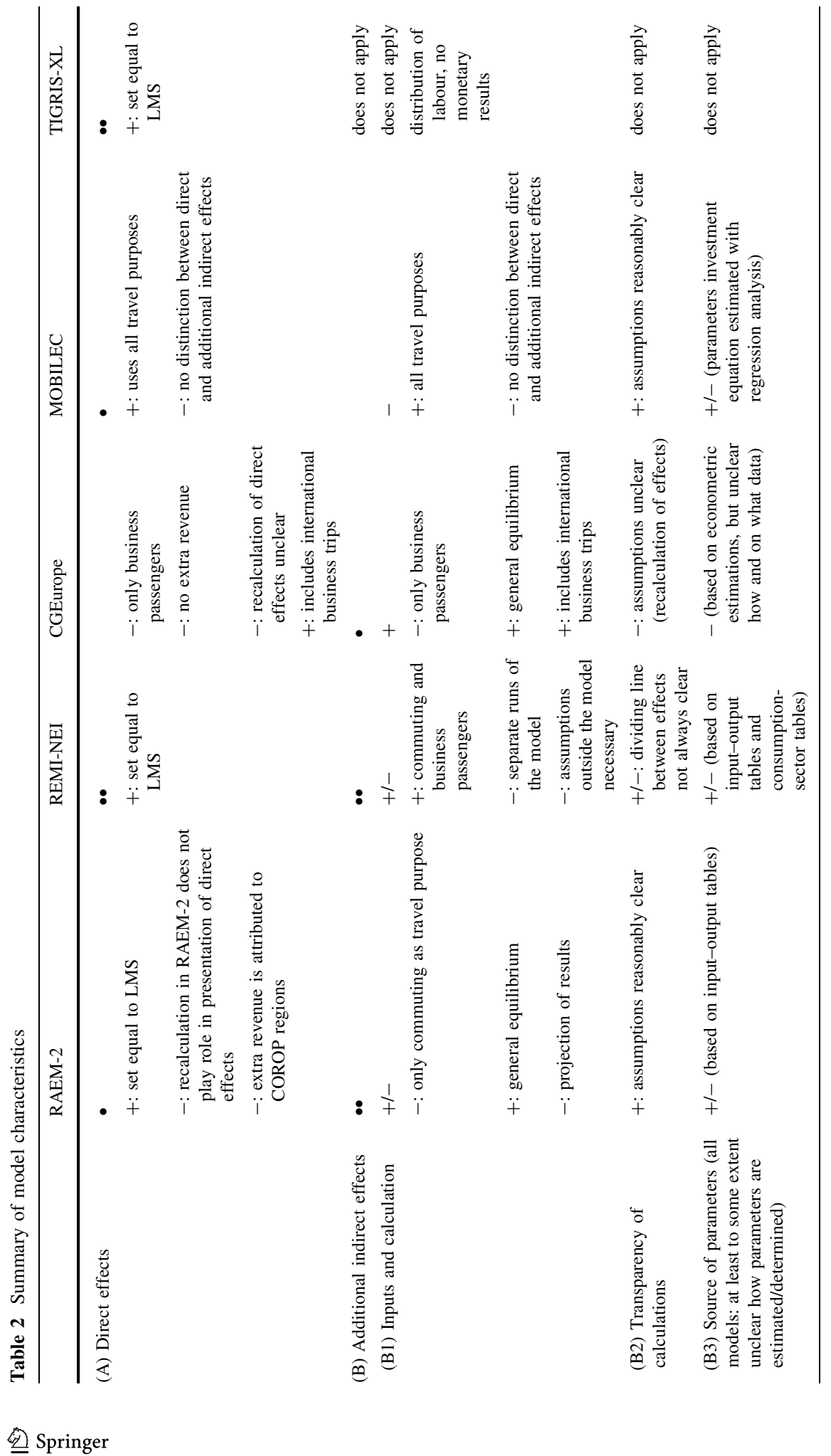




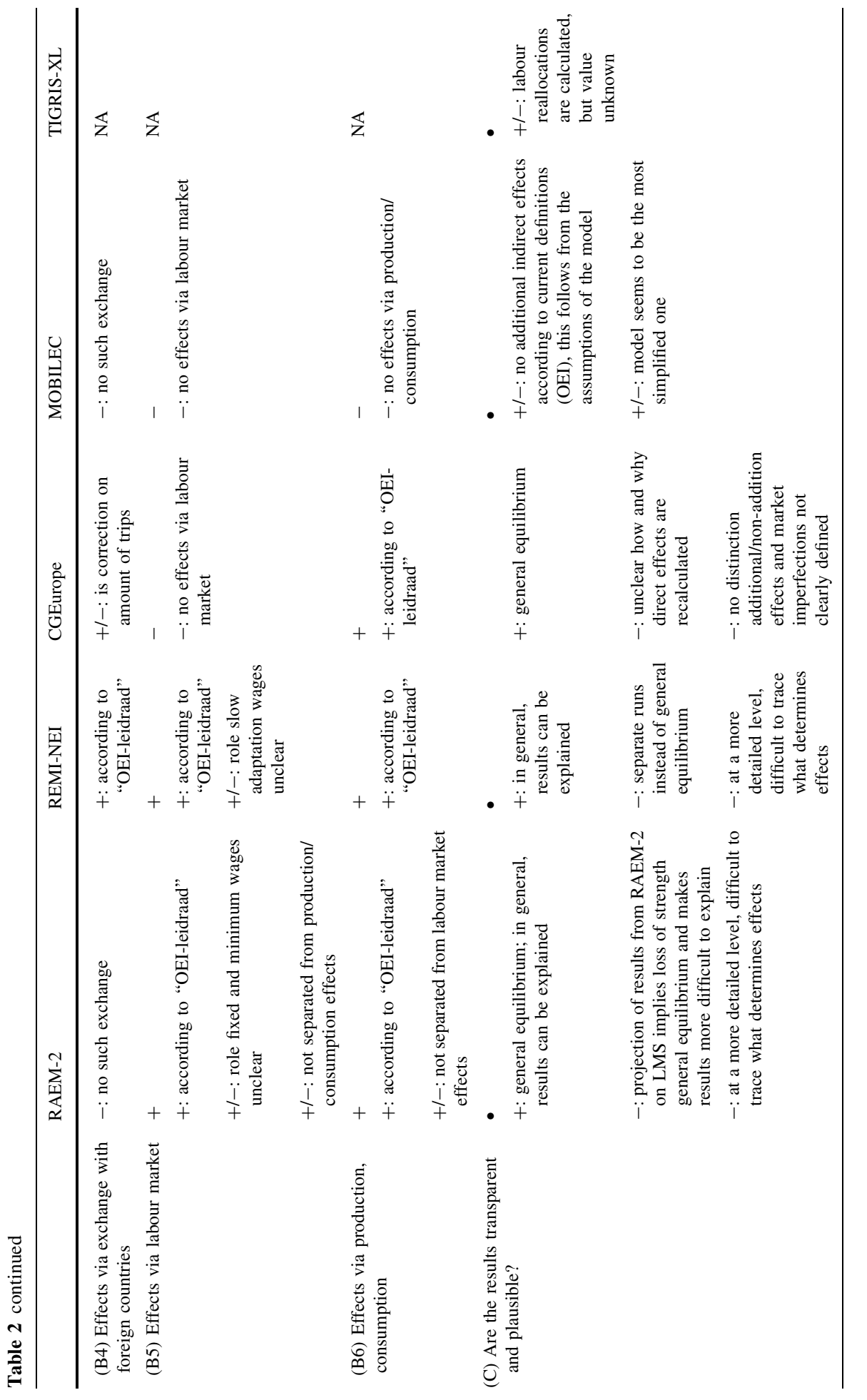




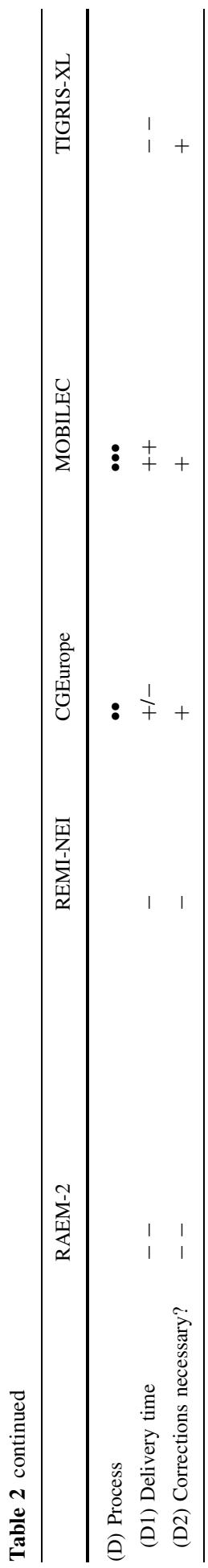

Springer 
Open Access This article is distributed under the terms of the Creative Commons Attribution Noncommercial License which permits any noncommercial use, distribution, and reproduction in any medium, provided the original author(s) and source are credited.

\section{References}

Bork, G., Van Treyz, F.: The REMI model for the Netherlands. In: Van Oort, F., Thissen, M., Van Wissen, L. (eds.) A Survey of Spatial Economic Planning Models in the Netherlands, Theory, Application and Evaluation. NAi, Rotterdam, ISBN 90-5662-376-1. http://www.pbl.nl/publicaties/2005/A-survey-ofspatial-economic-planning-models-in-the-Netherlands (2005). Accessed 20 April 2011

Bröcker, J.: Spatial effects of European transport policy: a CGE approach. In: Hewings, G., et al. (eds.) Trade, Networks and Hierarchies. Springer, New York (2002)

Daly, A., Sillaparcharn, P.: National models. In: Hensher, D., Button, K. (eds.) Handbook of Transport Modelling. Pergamon, Amsterdam (2008)

Dixit, A.K., Stiglitz, J.E.: Monopolistic competition and optimum product diversity. Am. Econ. Rev. 67, 297-308 (1977)

Eddington, R.: The Eddington Transport Study: Main Report: Transport's Role in Sustaining the UK's Productivity and Competitiveness. HMSO, London (2006)

Eijgenraam, C., Koopmans, C., Tang, P., Verster, N.: Evaluation of Infrastructural Projects; Guide for CostBenefit Analysis; Section I: Main Report; Section II: Capita Selecta. Research Programme on the Economic Effects of Infrastructure. Dutch Ministry of Transport, The Hague (2000)

Elhorst, J.P., Heyma, A., Koopmans, C., Oosterhaven, J.: Indirecte effecten infrastructuurprojecten, aanvulling op de Leidraad OEI [Indirect Effects of Infrastructure Projects, Addition to the OEI Guidelines]. Ministry of Economic Affairs and Ministry of Transport, The Hague (in Dutch) (2004)

Fan, W., Treyz, F., Treyz, G.: An evolutionary new economic geography model. J. Reg. Sci. 40(4), 671-695 (2000)

Flyvbjerg, B., Bruzelius, N., Rothengatter, W.: Megaprojects and Risk: An Anatomy of Ambition. Cambridge University Press, Cambridge (2003)

Graham, D.J.: Wider Economic Benefits of Transport Improvements: Link Between Agglomeration and Productivity, Stage 1 Report. Centre for Transport Studies, Imperial College London, London (2005)

Heyma, A., Oosterhaven, J.: Social cost-benefit analysis and spatial-economic models in the Netherlands. In: Van Oort, F., Thissen, M., Van Wissen, L. (eds.) A Survey of Spatial Economic Planning Models in the Netherlands, Theory, Application and Evaluation. NAi, Rotterdam, ISBN 90-5662-376-1. http://www. pbl.nl/publicaties/2005/A-survey-of-spatial-economic-planning-models-in-the-Netherlands (2005). Accessed 20 April 2011

Hof, B., Heyma, A.: Case study indirecte effecten van investeringen in infrastructuur, doorrekening en vergelijking van de case personenvervoer [Case Study Indirect Effects of Investments in Infrastructure, Quantification and Comparison of the Case Passenger Travel]. Report 2008-20 SEO Economisch Onderzoek, Amsterdam (in Dutch, with English summary). http://www.seo.nl/pagina/article/casestudy-indirecte-effecten-van-investeringen-in-infrastructuur/ (2008). Accessed 20 April 2011

Jara-Díaz, S.R.: Transport Economic Theory. Elsevier, Amsterdam, ISBN: 9780080450285 (2007)

Oosterhaven, J., Knaap, T., Ruijgrok, C., Tavassy, L.: On the development of RAEM: the Dutch spatial general equilibrium model and it's first application to a new railway link. Paper presented on the 41th congress of the European Regional Science Association (2001)

Rouwendal, J.: Indirect Welfare Effects of Price Changes and Cost-Benefit Analysis. Tinbergen Institute Discussion Paper 2002-011/3, Vrije Universiteit, Amsterdam (2002)

SACTRA: Transport and the economy, Full report. Standing Advisory Committee for Trunk Road Assessment, UK Department for Transport. http://webarchive.nationalarchives.gov.uk/200503011929 06/http:/dft.gov.uk/stellent/groups/dft_econappr/documents/pdf/dft_econappr_pdf_022512.pdf (1999). Accessed 20 April 2011

Talvitie, A.: Things planners believe in, and things they deny. Transportation 24, 1-31 (1997)

Thissen, M.: RAEM: regional applied general equilibrium model for the Netherlands. In: Van Oort, F., Thissen, M., Van Wissen, L. (eds.) A Survey of Spatial Economic Planning Models in the Netherlands, Theory, Application and Evaluation. NAi, Rotterdam, ISBN 90-5662-376-1. http://www.pbl.nl/public aties/2005/A-survey-of-spatial-economic-planning-models-in-the-Netherlands (2005). Accessed 20 April 2011

Van de Vooren, F.: Modelling transport in interaction with the economy. Transp. Res. E 40(5), 417-437 (2004) 
Van der Hoorn, A., Schoemaker, A.: Land use transportation interaction models: the succession of TIGRIS, Results from the feasibility study by Free University of Amsterdam, RAND Europe, MuConsult. Paper for the 29th Colloquium Vervoersplanologisch Speurwerk, Amsterdam, 28-29 November 2002, pp. 1065-1084. http://www.cvs-congres.nl/cvs/page/4/bibliotheek (search for TIGRIS) (2002)

Webster, V., Bly, P., Paulley, N. (eds.): Urban Land-Use and Transport Interaction: Policies and Models. Report of the ISGLUTI Study, Avebury (1988)

Willigers, J., de Bok, M.: Updating and extending the disaggregate choice models in the Dutch National Model. In: Proceedings of the European transport conference 2009, Noordwijkerhout. http:// www.etcproceedings.org/paper/updating-and-extending-the-disaggregate-choice-models-in-the-dutchnational-mo (2009). Accessed 20 April 2011

Zondag, B.: Joint modeling of land-use, transport and economy. Dissertation T2007/4, April 2007, TRAIL Research School, the Netherlands (2007)

Zondag, B., Geurs, K., De Jong, G., De Bok, M., Pieters, M.: Accessibility appraisal: there's more to it than just summing up travel cost reductions. In: Proceedings of the European Transport Conference 2007, Noordwijkerhout. http://www.etcproceedings.org/paper/accessibility-evaluation-there-s-more-to-it-thanjust-summing-up-travel-cost-r (2007). Accessed 20 April 2011

\section{Author Biographies}

Bert Hof is employed at SEO Economic Research, at the unit Competition and Regulation Policy. He is the main author of the research on which this article is based. Part of his activities involve cost-benefit analysis, be it in the form of applications, second opinions, methodology or empirical underpinnings.

Arjan Heyma is employed at SEO Economic Research, at the unit Labour and Education. He is author of the OEI Guidelines on indirect effects of infrastructure projects and co-author of the research on which this article is based. He specializes in labour dynamics, social security and regional developments.

Toon van der Hoorn is employed at Rijkswaterstaat (the Public Works Department of the Ministry of Infrastructure and Environment). He works on transport model development, both on the national and regional level. He is also part-time professor in transportation economics at the University of Amsterdam. 